\title{
On the Construction of Aesthetic Theories under Multiple
}

\section{Contexts}

\author{
Lei Xiao ${ }^{1,2^{*}}$ \\ ${ }^{1}$ Tianjin Economics \& Trade school, Tianjin, China \\ ${ }^{2}$ Beijing Normal University, Beijing, China \\ *Lei Xiao, E-mail: XL0125@VIP.QQ.COM
}

Received: August 6, 2017

Accepted: August 16, 2017 Online Published: August 18, 2017

doi:10.22158/wjer.v4n3p460

URL: http://dx.doi.org/10.22158/wjer.v4n3p460

\begin{abstract}
Aesthetics is a comprehensive discipline about aesthetic phenomena with diverse and synthetic research methods. Compared with the general humanity disciplines, aesthetic studies pay more attention to perceptual experience, emotional conformity and psychological collision, and requires more cooperation and assistance of empirical science. This paper starts from different cultures under multiple contexts to expound on aesthetic understandings and perceptions from different aspects.
\end{abstract}

\section{Keywords}

aesthetics, multiple contexts, artistic spirit, aesthetic form

\section{Introduction}

The existence of aesthetics is very universal. In a sense, aesthetics, as perceptual display of concepts, refers to the objects and properties that can trigger sensory or five sense organs excitement. Aesthetic activities are natural requirement of human spirit, so aesthetics is human perception and display of human emotions to objects. Under the influence of multiple contexts and cultures, there is extensive and profound aesthetics everywhere. And the factors causing the differences in the forms of aesthetic theories in different places include thinking mechanism and value tendency of construction, features and functional awareness of multiple contexts, structure and derivative tendency of paradigm and internal spirit of artistic practice.

\section{Thinking Mode and Culture}

Westerners hold that the subject and object are contradictory, and the object is to be conquered and utilized. This binary thought of subject and object is deeply rooted in the blood of westerners, forming a traditional thinking mode. Their cultural tendencies are that the subject can understand truth and endow order upon the object; rationality and logic are necessary means to cognize truth; abstract 
knowledge system supersedes concrete existence; sequential structure is organized based on logic within the system. Western culture holds that to conquer you must cognize first. To explore into and grasp the object, the perceptual region must be transcended to get into the thinking area of rationality and interpret concrete experience into abstract concepts and procedures.

In their mind, aesthetics is one type of knowledge to be classified and analyzed with clear-cut theories and organized with strict logic, so as to sublimate the uncertain objects into the paradigm of rationality. Cases in point include Poetics of Aristotle and Aesthetics of Hegel.

Chinese philosophers hold that humankind is just a part of the world, the product of the universe featuring circulation of creation and transformation, so the subject and the object have to be unified. "The heaven and the earth are born together with me and everything on earth is combined into one with me", so humankind can move with "Dao". The world can not be understood through rational analyses. This thinking mode can be called "holistic and intuitive thinking" that stresses overall understanding as a primitive systemic thinking. They pay attention to reasoning based on "mode" and "analogy", generally starting from a basic mode and gradually expanding and deepening to complete the cognition through a series of contradictory actions like image combinations and intuitive judgments. Philosophers argue that aesthetics is the natural display of "Dao", "Qi" and rhythms of the universe. As long as humankind maintain an aesthetic mind, they will be able to cognize.

Chinese aesthetics stresses that "there are changes in unity and vice versa", i.e., the relationship between integrality and individuality of architecture. Chinese ancient architecture pays attention to the unity of heaven and humankind, which is displayed not only in the overall layout and construction but also in every individual member of it. Chinese ancient architecture, as a whole, stresses following the local conditions by integrating into the natural environment without constraint in dot-mode layout instead of regarding location as the criterion, so as to achieve harmony and unity with nature. Speaking from cultural character, Chinese traditional aesthetics is introverted and reserved, and there is no exception to architectural aesthetics that is characterized by reserved and secluded features. Chinese ancient architecture stresses the doctrine of mean featured by "unity of heaven and humankind", integration into nature as well as reservation and seclusion. For example, the fengshui theory advocates that "a house should be built on a place unrounded by mountains and rivers" and "zigzagging" path leades to seclusion; the mountains have to be winding, the waters have to be lingering, the paths have to be surprising at a turn, the bridges have to be arching, and the corridors have to be soul-stirring. These display the harmonic beauty with nature by following the local conditions without any deliberate arrangements. Only by this, will it contain the beauty of restraint and reservation without displaying any affectation or flamboyance.

The thought of "unity of heaven and humankind" is an important topic in Chinese philosophy. It advocates the harmony and unity between humankind and the nature. When put it in the context of human society, it pursues the super human kindness and beauty, i.e., pursuing the acme of beauty and the perfect harmony with the nature. 
John Dini commented that "Chinese never force to build any systemic literary theories. Perhaps making paradigms or erecting general rules may destroy the fragile specificity of every work and obliterate its individual value". Although he was discussing literature, it could also be used to explain aesthetics.

The philosophical foundation of contemporary Chinese aesthetic theories is based on Marxist historical materialism. Specifically speaking, they take Marxist theories of practice and ontology as the mainstay and meanwhile absorb the essence of various philosophical thoughts in the human intellectual history.

\section{Multiple Contexts}

The combination ways of linguistic words have certain isomorphic relationship with cultural-psychological structure, and they are also the physicalized existence form of theories, which was labeled as "language prison" by Heidegger. It is extremely difficult to jump out of the prison, the "house of existence", to conduct theoretical activities. Therefore, we can take advantage of the specific features and functional concepts of Chinese and western linguistic words to analyze the differences in their aesthetic theoretical forms.

Western thinkers hold that the path of cognizing truth moves from perceptual to rational, and the highest level of rationality turns out to be a clear-cut linguistic semiotic system. They have special dependence upon linguistic symbols, and they feel more eased at more detailed analyses and more precise reasoning. Moreover, the western language grammar is very strict, so their theories are normally analytic, illustrative and empirical, with a view to allowing people to understand not only the results but also the process and train of thought.

Chinese philosophers are aware of the language limitations, as "Dao can not be put into words, and what can be put into words is not Dao any more". To aesthetic objects, "The Dao that can be told is not the eternal Dao; and the Name can be named is not the eternal Name". To aesthetic subjects, "meaning is not fully expressed in words". To creators, "no traces of efforts are left in words". To receptors, "the words are forgotten in obtaining the meaning". There is a awareness of transcending linguistic symbols.

\section{Artistic Spirit}

The artistic beauty in aesthetic theories focuses on the aesthetic awareness in art and the inner spirit of art. The differences in aesthetic awareness and inner spirit shown by Chinese and western arts also lead to the differences in aesthetic theories.

There is always some type of "metaphysical" pursuit in Chinese art, hoping to move the finite into infinite. And Chinese poems and prose also pursue "image out of image", "flavor out of rhymes" while paintings pursue the "conception", "ease of manner" and "spirit" with an obsession of emptiness. The key of Chinese paintings lies in grasping the lines and ink color, but in essence it is about grasping the "Dao" and "Qi" as demonstrated by "one painting covers all in and outside the primordial worlds", full of awareness of transcendence.

Western arts pursue integrity and clearness, as demonstrated in the neat formation, regulation and 
symmetry of western architectures, glitering the shine of rationality. Lingering among them, you seem to see the spirit of Euclid. Modern western arts pursue irrationality, but it still uses rationality to prove the reasonableness of irrationality. Therefore, arts out of irrational creation can still be grasped by rationality, as evidenced by the slogan of "theories over creation".

Hence, the differences between Chinese and western artistic spirits will no doubt influence the theoretical forms of aesthetics. From the angle of theoretical form, Chinese aesthetics enjoy a larger potential while western aesthetics boasts practical significance.

\section{Thoughts and Its Changes of Formal Beauty}

Formal beauty has been a key issue in both history of western aesthetics and art philosophy, but it remains a disputing topic. Philosophers and aestheticians in ancient Greek hold that beauty is form, and tend to regard form as the essence of beauty and art. According to the Pythagorean school, art comes from numbers and their harmony, while their harmony involves form. The mainstream culture in the Middle Ages is Christian culture, and in the period the God becomes the prescription of beauty and all arts, practical rationality becomes the prescription of thought, hence differentiating itself from the stress on practical life in ancient Greek. From ancient times to the Middle Ages, western aesthetics and art philosophy move into a new era, when the aesthetics is included into theology displayed as the combination of Plato doctrines, neo-Platonism of Plotinus and Christian thoughts, hence forming the tendency of mystification.

Modern aesthetics refers to the period from Renaissance to the end of 19th century, when aesthetics in its true sense got started. In modern times, "form" has become an independent paradigm in aesthetics uplifted to the height of essence of arts consciously and rationally. From Renaissance, the human nature is revived and awakened, and rationality becomes the prescription of thoughts. This rationality is one type of creative rationality different from the theoretical rationality in ancient Greek and practical rationality in the Middle Ages. In modern times, western formal aesthetics has witnessed significant development, especially in terms of regarding form as pure and transcendental. The influence is far more significant than the aesthetic experience and awareness in modern empirical aesthetics.

In modern times, existence becomes the prescription of beauty, and aesthetic thoughts are spread over dimensions and contexts. Meanwhile, western formal aesthetics also sees new development, namely emergence of structuralist aesthetics, analytic aesthetics and Gestalt Psychology aesthetics. Some fundamental issues related with aesthetics and arts have walked out of traditional constraints to enter into the area of existence. If we say modern aesthetics is still paying attention to form in the context of existence, then post-modernism sticks to a strong anti-form trend. Post-modern arts becomes arts of behavior and participation, and it seems to have no need of aesthetic standard or "art rationality". Post-modernism opposes centrality, dualism or systematism, dispels the basic viewpoints of traditional and modern aesthetic thoughts and artistic theories, and strives to deconstruct all formal rules of aesthetics. 
Form is the representation of beauty and art, and it is closely related with the essence of the latter, so as to reveal the existence of art and beauty. Seen from the aspects of thought development course and relevance forms of formal beauty, there are insurmountable obstacles for form to prescribe art, for the relevance between form and art is extremely complicated.

\section{Aesthetic Form}

The aesthetic perception mainly comes from nature and art, and the former comes out of natural formation and the latter out of human creation.

Artistic beauty serves as one way for humankind to understand and grasp the world, and it aims for better cognizing the world and deepening the significance of human existence as a way of understanding and creating life. Artistic beauty refers to the beauty contained in artworks created by artists through nature and expression of individual subjective awareness. Artistic beauty is the essence of artworks that reflect the world and summarize human feelings of the world. Therefore, artistic beauty is a feeling of human subjective summrization of things and then re-creation in accordance with human aesthetic practice. Artistic beauty can constantly improve human aesthetic capacity, deepen and change aesthetic requirements, which will further promote artists to expand the artworks in a more advanced and diverse manner. In this mutually promoting manner, art will move forward and artistic beauty will be uplifted constantly.

Natural beauty is the masterpiece of nature as well as natural formation, a beauty that can be perceived by humankind for conformity with human aesthetic tastes. It reveals the life strength of great nature and contains huge life vitality. Human passion for natural beauty is the worship for natural life. Natural beauty is not created by humankind, and natural beauty displays the beauty of life. There is almost no estrangement between humankind and nature, for humankind is part of nature. Humankind is good at locating beauty in nature and spiritual paradise from it too. Only when natural beauty is appreciated by humankind, will deeper meaning be attached to it. To humankind, natural beauty is a marvelous artwork created by nature itself.

Social beauty exists in the area of society, including culture and world created by humankind as well as humankind itself. Beauty has always been social in nature, and social beauty is displayed in all historical activities of humankind in conducting social activities. In addition, beauty is closely related with people's daily life. Although they are different, it is difficult to separate, for it is often shown as life beauty of humankind. Society is an integral of humankind, things and objects, so it is equal to humankind, culture and world. Hence, society is life itself of humankind and the culture and world created by humankind. It is the practical place for displaying beauty.

There have been many new changes and relations among artistic beauty, social beauty and natural beauty. On the one hand, humankind and nature are not just in a relationship featuring utilization, conquering or contradiction, but they are in a partnership and harmony. They belong to the same ecology featuring closer and closer neighborhood instead of being remotely separated. On the other 
hand, the relationship between social reality and art has been closer, for the former now also needs the latter. It can be said that artistic beauty contains social beauty and natural beauty yet it is still different from the them.

The biggest social function and value of aesthetics lies in aesthetic cultivation, which can not only shape human character and individuality, but also bring to people joyful emotions as well as healthy and active mental attitude. Whether for natural beauty or artistic beauty, we should actively observe and study them so as to uplift our artistic creativeness and appreciation ability.

\section{References}

Adorno. (1998). Aesthetics theory. Sichuan people's press.

Ellen, D. (2004). Aesthetic. The Commercial Press.

Miguel, D. (1985). Aesthetics and philosophy. Chinese Social Sciences Press.

Osborn. (2006). Art of appreciation. Sichuan people's press. 